\title{
Penerapan Analitycal Hierarchy Process (Ahp) dalam Menentukan Lokasi Pabrik Tempe
}

\author{
Cahyaning Kilang Permatasari \\ Teknik Industri, Fakultas Teknik, Universitas Nahdlatul Ulama, Surakarta, Indonesia \\ E-mail: kilangcahyaning@gmail.com
}

Informasi naskah:

Diterima

3 Juli 2020

Direvisi

10 Agustus 2020

Disetujui terbit

20 Agustus 2020

Diterbitkan

31 Agustus 2020

\begin{abstract}
Nowadays, tempe household industry entrepreneurs must choose the right factory location. Location is very influential for develop of a company, besides it can minimize problems in the future. The purpose of this study was to determine the percentage of priority criteria in selecting factory locations. The results of the calculation of priority criteria, it is hoped that entrepreneurs will find it easier to determine a suitable location to build a tempe factory. This research was conducted in Karanganyar Regency. The method used to determine the priority criteria for selecting the tempe factory location is Analytical Hierarchy Process (AHP) method. After through the process of obtaining data and analyzing calculations using Microsoft Excel, the percentage result of the criteria are geological and climatic conditions (34.67\%), availability of labor $(26.94 \%)$, market and marketing distance (14.93\%), transportation facilities (11.36\%), supporting facilities and utilities $(7.08 \%)$ and distance to the location of raw material suppliers (5.02\%). This criterion combines several aspects based on the level of importance, so that the results of the order in selecting the location of the tempe factory will be more objective.
\end{abstract}

Keywords: AHP, Tempe, IRT, factory eligibility

\section{PENDAHULUAN}

\subsection{Latar Belakang Masalah}

Industri tempe merupakan salah satu industri yang banyak diminati oleh masyarakat untuk dijadikan mata pencaharian. Selain bahan baku yang mudah dan murah untuk didapat, industri ini memiliki profit yang cukup tinggi. Kebanyakan industri tempe merupakan Industri Rumah Tangga (IRT). IRT merupakan salah satu penopang perekonomian daerah yang membutuhkan dukungan agar dapat bertumbuh menjadi lebih besar. Menurut Badan Pusat Statistik (BPS), jenis usaha dibedakan menjadi usaha rumah tangga yang memiliki satu sampai lima tenaga kerja, usaha kecil memiliki enam sampai 19 tenaga kerja, usaha menengah memiliki 20 sampai 29 tenaga kerja dan usaha besar 
memiliki lebih dari 100 tenaga kerja ${ }^{1)}$. Perbedaan yang mendasar lainnya dapat dilihat pada tabel berikut ${ }^{2)}$ :

Tabel 1. Perbedaan Jenis Usaha

\begin{tabular}{cccc}
\hline No. & Usaha & Aset & Omset \\
\hline 1. & Usaha Mikro & Maksimal 50 juta rupiah & Maksimal 300 juta rupiah \\
2. & Usaha Kecil & 50 juta rupiah s/d 500 juta & 300 juta rupiah s/d 2,5 miliar \\
& rupiah & rupiah \\
3. & Usaha & 500 juta rupiah s/d 10 miliar & 2,5 miliar rupiah s/d 5 miliar \\
& Menengah & rupiah & rupiah \\
\hline
\end{tabular}

Dalam perkembangannya, produk tempe dapat diekspor ke beberapa negara. Seperti yang tertulis dalam laman berita CNBC Indonesia - 09 January 2020 pukul 20:18 WIB oleh Efrem Siregar, Menteri Perindustrian Agus Gumiwang menyatakan keinginannya untuk mengekspor tempe. Beliau juga menyampaikan bahwa fasilitas pada pabrik tempe harus layak, sehingga memenuhi standar higienis ${ }^{3)}$.

Untuk mendukung industri tempe agar dapat bertumbuh menjadi lebih besar bahkan dapat diekspor serta memenuhi standar higienis, hal pertama yang diperhatikan adalah tentang lokasi pabrik tempe harus berada di lokasi yang tepat. Dari pengamatan yang sudah dilakukan, khususnya di Kabupaten Karanganyar, lokasi pabrik tempe masih berada di kawasan pemukiman. Hal ini akan menjadi hambatan pabrik tempe untuk dapat bertumbuh, maka perlu dilakukan pemilihan lokasi pabrik tempe yang tepat agar semua tujuan tersebut dapat tercapai. Dalam buku yang berjudul "Analisis Kelayakan Pabrik" yang ditulis oleh M. Sayuti, Edisi Pertama, 2008 menjabarkan bahwa, aspek yang perlu diperhatikan dalam kelayakan pabrik adalah aspek teknis, pasar dan pemasaran, yuridis, manajemen, lingkungan serta finansial. Sedangkan lokasi pabrik sendiri merupakan bagian dari aspek teknis dan teknologi ${ }^{4)}$.

Ada beberapa kriteria yang harus diperhatikan saat akan menentukan lokasi pabrik tempe, agar kelangsungan industri tempe kedepannya semakin maju dan meminimalkan permasalahan dimasa depan. Dengan mengetahui prosentase prioritas kriteria yang harus diutamakan dalam pemilihan lokasi pabrik, diharapkan para pengusaha akan lebih mudah saat menentukan lokasi mana yang cocok untuk mendirikan pabrik tempe mereka. Barubaru ini telah banyak penelitian yang dilakukan mengenai penentuan skala prioritas dengan metode Analitycal Hierarchy Process (AHP), sebagai sebuah metode yang diperlukan agar dapat menampung semua aspek. Selanjutnya diharapkan dapat disusun urutan kriteria yang sesuai kebutuhan. Dengan beberapa kelebihan AHP sebagai penentu prioritas kriteria maka penelitian ini menerapkan AHP sebagai penentuan prioritas kriteria lokasi pabrik, oleh karena itu penelitian ini mengambil judul "Penerapan Analitycal Hierarchy Process (AHP) Dalam Menentukan Lokasi Pabrik Tempe”. 


\subsection{Identifikasi Permasalahan}

Berdasarkan latar belakang masalah di atas, maka permasalahan dalam penelitian ini adalah bagaimana urutan kriteria dalam menentukan prioritas lokasi pabrik tempe?

\subsection{Batasan Penelitian}

Batasan masalah dalam penelitian ini sebagai berikut :

1. Objek pengamatan adalah di Kabupaten Karanganyar.

2. Analisa AHP hanya pada kriteria, tidak dengan alternative lokasi pabrik tempe.

\subsection{Tujuan dan Manfaat Penelitian}

Tujuan penelitian ini adalah mengetahui hasil skala kriteria prioritas lokasi pabrik tempe. Manfaat penelitian ini adalah memberikan informasi tentang skala kriteria prioritas lokasi pabrik tempe.

\section{METODE}

Penelitian ini dilakukan dengan mengamati lokasi di Kabupaten Karanganyar Provinsi Jawa Tengah karena Kabupaten Karanganyar banyak terdapat industri pengolahan tempe. Letaknya yang strategis membuat Kabupaten Karanganyar sangat baik untuk pengembangan industri tempe.

\subsection{Pengumpulan Data}

Metode pengumpulan data yang digunakan pada penelitian ini adalah:

1. Observasi adalah aktivitas terhadap suatu proses atau objek dengan maksud merasakan dan kemudian memahami pengetahuan dari sebuah fenomena berdasarkan pengetahuan dan gagasan yang sudah diketahui sebelumnya, untuk mendapatkan informasi yang dibutuhkan untuk melanjutkan suatu penelitian ${ }^{5)}$.

2. Wawancara adalah suatu kegiatan dilakukan untuk mendapatkan informasi secara langsung dengan mengungkapkan pertanyaan pada responden. Wawancara bermakna berhadapan langsung antara interview dengan responden, dan kegiatannya dilakukan secara lisan ${ }^{6)}$.

3. Kuesioner dengan skala Analytical Hierarchy Process AHP yang dibagikan langsung kepada responden ${ }^{7)}$.

Responden yang dipilih adalah sebagai berikut:

1. Pengusaha tempe usia 70 tahun, menjalankan usahanya lebih dari 20 tahun.

2. Pengusaha tempe usia 43 tahun, menjalankan usahanya sekitar hampir lima tahun.

3. Anggota Primer Koperasi Produsen Tempe dan Tahu Indonesia (PRIMKOPTI) dengan usia 55 tahun.

4. Konsumen tempe dengan usia 55 tahun. 


\subsection{Analytical Hierarchy Process (AHP)}

Pengambilan keputusan adalah suatu proses pemikiran dalam rangka pemecahan suatu masalah untuk memperoleh hasil akhir guna dilaksanakan ${ }^{8)}$. Menurut Taylor (2014), AHP adalah sebuah metode untuk memeringkat alternatif keputusan dan memilih yang terbaik dengan beberapa kriteria ${ }^{9)}$. AHP mengembangkan satu nilai numerik untuk memeringkat setiap alternatif keputusan, berdasarkan pada sejauh mana tiap-tiap alternatif memenuhi kriteria pengambil keputusan. Sedangkan menurut Nugeraha (2017), AHP adalah sebuah konsep untuk pembuatan keputusan berbasis multicriteria (kriteria yang banyak). Beberapa kriteria yang dibandingkan satu dengan lainnya (tingkat kepentingannya) adalah penekanan utama pada konsep AHP.

\subsection{Prinsip Dasar Analytical Hierarchy Process (AHP)}

Pertama adalah penyusunan hierarki, dengan hirarki, suatu masalah yang kompleks dapat diuraikan ke dalam kelompok-kelompoknya yang kemudian diatur menjadi suatu bentuk hirarki sehingga permasalahan akan tampak lebih terstruktur dan sistematis ${ }^{10}$. Menurut Saaty (1994) dalam Hanien Nia H Sega (2012) menjelaskan hirarki adalah gambaran dari permasalahan yang kompleks dalam struktur banyak tingkat dimana tingkat paling atas adalah tujuan dan diikuti tingkat kriteria, subkriteria dan seterusnya ke bawah sampai pada tingkat yang paling bawah adalah tingkat alternatif ${ }^{11)}$. Berdasarkan latar belakang pada pendahuluan dapat ditentukan kriteria yang akan digunakan dalam "Penerapan Analitycal Hierarchy Process (AHP) Dalam Menentukan Lokasi Pabrik Tempe" dapat digambarkan dalam bagan Skema Hierarki "Penerapan AHP Dalam Menentukan Lokasi Pabrik Tempe" ditunjukan pada Gambar 1:

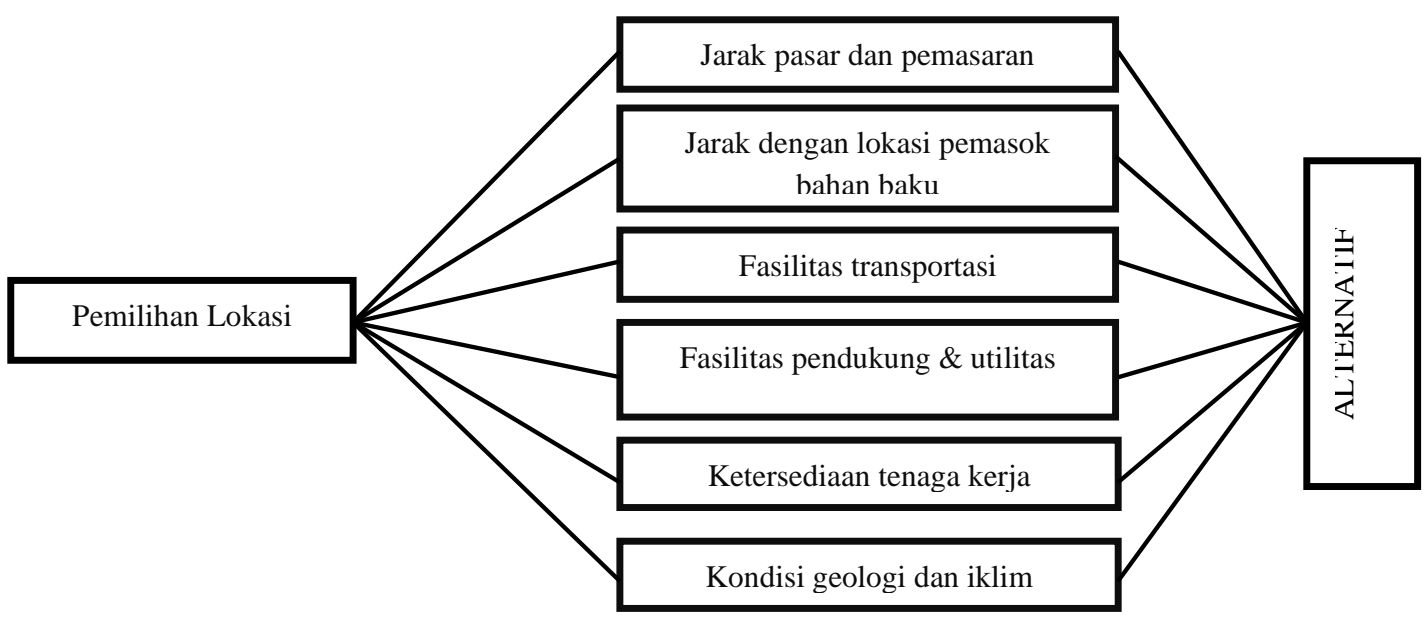

Gambar 1. Skema Hirarki "Penerapan AHP Dalam Menentukan Lokasi Pabrik Tempe"

Sebelum memilih aklternative lokasi atau tanah yang akan dijadikan lokasi pabrik, tentunya lokasi dan tanah yang dimaksud tersebut harus berada pada syarat yang sudah ditentukan pemerintah setempat. Dari beberapa sumber dan wawancara dengan responden 
maka dapat disimpulkan enam kriteria yang digunakan dalam menentukan loaksi pabrik tempe dalam penelitian ini, dengan keterangan sebagai berikut ${ }^{12)}$ :

1. Jarak pasar dan pemasaran akan mempengaruhi biaya distribusi dan biaya lainnya yang terkait dengan distribusi produk, maka akan meningkatkan biaya distribusinya.

2. Jarak lokasi pemasok bahan baku yang dekat akan menjamin stabilitas pasokan serta mengurangi biaya pengiriman.

3. Fasilitas transportasi ditinjau dari kelancaran moda transportasi mempengaruhi pendistribusian produk dari lokasi pabrik ke konsumen serta bahan baku ke lokasi pabrik.

4. Fasilitas pendukung dan utilitas yang dimaksud adalah kelengkapan seperti persediaan air, jaringan listrik, telekomunikasi dan pengolahan limbah.

5. Ketersediaan tenaga kerja yang terampil dalam industri sangat berpengaruh terhadap kelancaran produksi. Ketidaktersediaan tenaga kerja yang dekat dengan lokasi pabrik akan mengakibatkan pengusaha mendatangkan tenaga kerja dari jarak yang jauh dengan lokasi pabrik, hal ini dapat meningkatkan biaya yang berkaitan dengan upah tenaga kerja.

6. Kondisi geologi dan iklim seperti kontur tanah, suhu dan kelembaban merupakan pertimbangan penting dalam menentukan lokasi pabrik.

Kedua adalah penilaian terhadap kriteria, dalam melakukan perhitungan dengan metode AHP. Untuk mengkuantitatifkan pendapat kualitatif digunakan skala penilaian sehingga akan diperoleh nilai pendapat dalam bentuk angka/kuantitatif. Menurut Saaty (1986) untuk berbagai permasalahan skala 1 sampai dengan 9 merupakan skala terbaik dalam mengkualitatifkan pendapat, dengan akurasinya berdasarkan nilai RMS (Root Mean Square Deviation) dan MAD (Median Absolute Deviation) ${ }^{13)}$.

Ketiga adalah penentuan bobot kriteria dan prioritas pembuktian konsistensi perbandingan berpasangan dengan AHP, dengan langkah sebagai beikut:

$$
\begin{aligned}
& \mathrm{a}(\mathrm{ij})=\mathrm{Ai} / \mathrm{Aj} \text {, dengan }: \mathrm{i}, \mathrm{j}=1,2,3, \ldots \mathrm{n} \\
& \mathrm{Wi}=\mathrm{n} \sqrt{(\text { ai } 1} \mathrm{x} \text { ai2 } \mathrm{x} \text { ai3,...x ain }) \\
& \mathrm{Xi}=(\mathrm{Wi} / \Sigma \mathrm{Wi}) \\
& \lambda m a k s=\Sigma \text { aij.Xj }
\end{aligned}
$$

Terakhir adalah pembuktian konsistensi perbandingan dengan perhitungan kontrol terhadap Indek Consistensi (CI) dan Ratio Consistensi (CR) ${ }^{14)}$.

- Indek Consistensi $(\mathrm{CI})=(\lambda$ maks. $-\mathrm{n}) /(\mathrm{n}-1)$, dimana $\mathrm{n}=$ ukuran matrik.

- Ratio Consistensi (CR) = CI/RI, Nilai Ratio Consistensi (CR) harus lebih kecil dari $10 \%$, sesuai dengan syarat konsistensi yaitu harus lebih kecil dari 0,1 atau $10 \%$. 


\subsection{Kelebihan dan Kelemahan Analytical Hierarchy Process (AHP)}

AHP sebagai salah satu metode analisis mempunyai kelebihan dan kekurangan. Kelebihan dari metode AHP adalah struktur yang berhierarki, sebagai konsekuensi dari kriteria yang dipilih, sampai pada sub kriteria yang paling dalam, selain itu memperhitungkan validitas sampai dengan batas toleransi inkonsistensi sebagai kriteria dan alternatif yang dipilih oleh pengambil keputusan dan memperhitungkan daya tahan output analisis sensitivitas pengambilan keputusan ${ }^{15)}$. Hal ini sesuai dengan penelitian yang telah dilakukan oleh Suci Oktri Viarani dan Hilma Raimona Zadry dalam penelitian yang berjudul Analisis Pemilihan Pemasok Dengan Metode Analitycal Hierarchy Process Di Proyek Indarung VI PT. Semen Padang, yang menuliskan bahwa metode AHP (Analytical Hierarchy Process) merupakan metode yang sistematis dan tidak membutuhkan waktu yang lama, dan dapat memperlihatkan bobot prioritas dari kriteria dan pemasok yang terpilih $^{16)}$. Mentari Rika Noviandri, dkk dalam penelitian yang berjudul Analisis Pemilihan Supplier Metallic Box Menggunakan Fuzzy Analytic Hierarchy Process (AHP) yang menuliskan bahwa pemilihan supplier adalah permasalahan multi kriteria dimana setiap kriteria yang digunakan mempunyai kepentingan yang berbeda dan informasi mengenai hal tersebut tidak diketahui secara tepat ${ }^{17)}$. Dalam hal ini pemilihan supplier berdasarkan penawaran harga yang rendah sudah tidak efisien lagi. Untuk mendapatkan kinerja SCM yang maksimal harus menggabungkan kriteria lain yang relevan dengan tujuan perusahaan, maka perhitungan dilakukan menggunakan metode fuzzy AHP.

Sedangkan kelemahan metode AHP adalah ketergantungan model AHP pada input utamanya. Input utama ini berupa persepsi seorang ahli sehingga dalam hal ini melibatkan subyektifitas sang ahli. Selain itu, model menjadi tidak berarti jika ahli tersebut memberikan penilaian yang keliru. Selanjutnya, metode AHP ini hanya metode matematis tanpa ada pengujian secara statistik sehingga tidak ada batas kepercayaan dari kebenaran model yang terbentuk.

\section{PEMBAHASAN DAN DISKUSI}

\subsection{Hasil}

Setelah mengumpulkan jawaban dari kuisioner AHP yang diisi oleh responden. Selanjutnya penilaian terhadap kriteria tersebut disajikan dalam tabel berikut ini :

Tabel 2. Penilaian Kepentingan Kriteria

\begin{tabular}{|c|c|c|c|c|c|c|c|c|c|c|c|c|c|c|c|}
\hline \multirow{2}{*}{ RESP } & \multicolumn{15}{|c|}{ SKALA PENILAIAN } \\
\hline & A-B & $\mathrm{A}-\mathrm{C}$ & A-D & A-E & $\mathrm{A}-\mathrm{F}$ & $\mathrm{B}-\mathrm{C}$ & B-D & B-E & B-F & C-D & C-E & C-F & D-E & $\mathrm{D}-\mathrm{F}$ & E-F \\
\hline R. 1 & 5 & $1 / 3$ & $1 / 5$ & $1 / 5$ & $1 / 5$ & $1 / 5$ & $1 / 7$ & $1 / 7$ & $1 / 5$ & $1 / 3$ & $1 / 3$ & $1 / 5$ & $1 / 3$ & $1 / 3$ & $1 / 7$ \\
\hline R. 2 & 3 & 3 & $1 / 3$ & 3 & $1 / 7$ & $1 / 3$ & $1 / 5$ & $1 / 3$ & $1 / 5$ & 3 & 1 & $1 / 7$ & $1 / 3$ & $1 / 7$ & 3 \\
\hline R. 3 & 3 & $1 / 3$ & $1 / 7$ & $1 / 3$ & $1 / 3$ & $1 / 3$ & $1 / 7$ & $1 / 5$ & $1 / 3$ & 5 & $1 / 5$ & $1 / 3$ & $1 / 9$ & $1 / 5$ & $1 / 9$ \\
\hline R. 4 & 3 & 5 & 3 & $1 / 3$ & $1 / 5$ & $1 / 3$ & 3 & $1 / 5$ & $1 / 5$ & 3 & $1 / 5$ & $1 / 7$ & $1 / 7$ & $1 / 5$ & 3 \\
\hline$\Sigma$ Resp & 14.00 & 8.67 & 3.68 & 3.87 & 0.88 & 1.20 & 3.49 & 0.88 & 0.93 & 11.33 & 1.73 & 0.82 & 0.92 & 0.88 & 6.25 \\
\hline Resp/4 & 3.50 & 2.17 & 0.92 & 0.97 & 0.22 & 0.30 & 0.87 & 0.22 & 0.23 & 2.83 & 0.43 & 0.20 & 0.23 & 0.22 & 1.56 \\
\hline
\end{tabular}

Langkah selanjutnya adalah mencari bobot kriteria dan pembuktian konsistensi perbandingan berpasangan dengan AHP. Kriteria dihitung masing-masing nilai 
konsistensinya. Nilai yang dipakai adalah pada rata-rata komulatif ( $\Sigma$ Resp/4) tersebut. Pada Matrik diagonal $\mathrm{AA}=\mathrm{BB}=\mathrm{CC}=\mathrm{DD}=\mathrm{EE}=\mathrm{FF}=1$, karena melakukan perbandingan dengan faktor diri sendiri.

Tabel 3. Matrik Awal Kriteria

\begin{tabular}{ccccccc}
\hline KRITERIA & $\mathrm{A}$ & $\mathrm{B}$ & $\mathrm{C}$ & $\mathrm{D}$ & $\mathrm{E}$ & $\mathrm{F}$ \\
\hline $\mathrm{A}$ & 1.00 & 3.50 & 2.17 & 0.92 & 0.97 & 0.22 \\
$\mathrm{~B}$ & 0.29 & 1.00 & 0.30 & 0.87 & 0.22 & 0.23 \\
$\mathrm{C}$ & 0.46 & 3.33 & 1.00 & 2.83 & 0.43 & 0.20 \\
$\mathrm{D}$ & 1.09 & 1.15 & 0.35 & 1.00 & 0.23 & 0.22 \\
$\mathrm{E}$ & 1.03 & 4.57 & 2.31 & 4.3448 & 1.00 & 1.56 \\
F & 4.57 & 4.29 & 4.88 & 4.5652 & 0.64 & 1.00 \\
\hline TOTAL & 8.44 & 17.83 & 11.01 & 14.53 & 3.49 & 3.44 \\
\hline
\end{tabular}

Selanjutnya adalah menghitung eigen Vektor dari tiap-tiap matrik awal kriteria.

Tabel 4. Nilai Eigen Vektor Kriteria

\begin{tabular}{cccccccccc}
\hline KRITERIA & $\mathrm{A}$ & $\mathrm{B}$ & $\mathrm{C}$ & $\mathrm{D}$ & $\mathrm{E}$ & $\mathrm{F}$ & $\Sigma$ & Wi & E-Vektor \\
\hline A & 1.00 & 3.50 & 2.17 & 0.92 & 0.97 & 0.22 & 1.48 & 1.07 & 0.14 \\
$\mathrm{~B}$ & 0.29 & 1.00 & 0.30 & 0.87 & 0.22 & 0.23 & 0.004 & 0.40 & 0.05 \\
C & 0.46 & 3.33 & 1.00 & 2.83 & 0.43 & 0.20 & 0.39 & 0.85 & 0.11 \\
$\mathrm{D}$ & 1.09 & 1.15 & 0.35 & 1.00 & 0.23 & 0.22 & 0.02 & 0.53 & 0.07 \\
E & 1.03 & 4.57 & 2.31 & 4.34 & 1.00 & 1.56 & 74.03 & 2.05 & 0.27 \\
F & 4.57 & 4.29 & 4.88 & 4.57 & 0.64 & 1.00 & 279.00 & 2.56 & 0.34 \\
\hline TOTAL & 8.44 & 17.83 & 11.01 & 14.53 & 3.49 & 3.44 & 354.92 & 7.45 & 1.00 \\
\hline
\end{tabular}

Nilai Eigen maksimum diperoleh dari matrik awal dikalikan dengan E-vektor masingmasing matrik dan kemudian hasil perkalian tersebut dijumlahkan. Pada penilaian kriteria adalah sebagai berikut:

Tabel 5. Penilaian kriteria

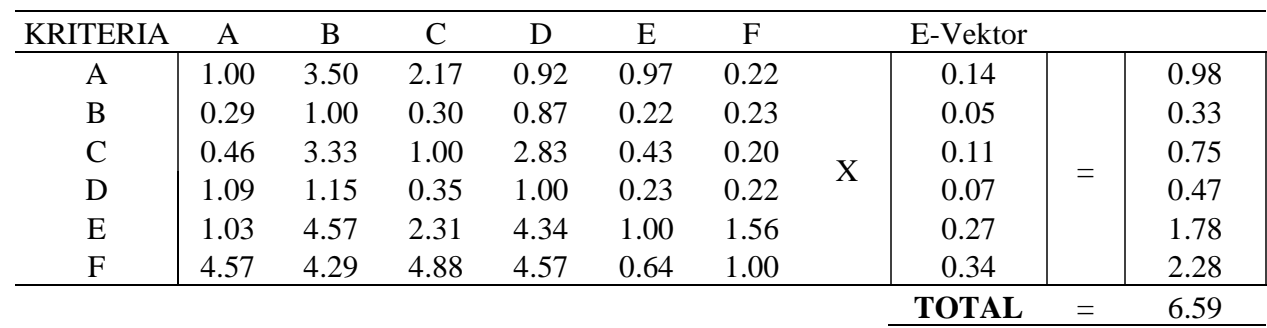

Eigen Maksimum $(\lambda$ maks $)=\Sigma$ aij. $X \mathrm{j}=6,59$

- Indek Consistensi $(\mathrm{CI})=(\lambda$ maks. $-\mathrm{n}) /(\mathrm{n}-1)$, dimana $\mathrm{n}=$ ukuran matrik $6 \times 6$

- Ratio Consistensi $(\mathrm{CR})=\mathrm{CI} / \mathrm{RI}$, untuk $\mathrm{n}=6$, maka RI $=1,24$. Nilai Ratio Consistensi (CR) lebih kecil dari 0,09 sama artinya lebih kecil dari 10\%, maka nilai tersebut sudah sesuai dengan syarat konsistensi yaitu harus lebih kecil dari 0,1 atau $10 \%$.

Pada penilaian kriteria

CI $=(6,59-6) /(6-1)=0,12$ 
Dapat dilihat bahwa penilaian responden terhadap kriteria dalam menentukan lokasi pabrik tempe adalah konsisten. Hasil dari bobot prioritas untuk kriteria yang telah dinormalisasikan disajikan pada Tabel 6. berikut:

Tabel 6. Bobot Kriteria

\begin{tabular}{l|lc}
\hline \multirow{5}{*}{ Kriteria } & Jarak pasar dan pemasaran & $0,98 / 6,59 \times 100 \%=\mathbf{1 4 . 9 3} \%$ \\
& Jarak lokasi pemasok bahan baku & $0,33 / 6,59 \times 100 \%=\mathbf{5 , 0 2} \%$ \\
& Fasilitas transportasi & $0,75 / 6,59 \times 100 \%=\mathbf{1 1 , 3 6} \%$ \\
& Fasilitas pendukung dan utilitas & $0,47 / 6,59 \times 100 \%=\mathbf{7 , 0 8} \%$ \\
& Ketersediaan tenaga kerja & $1,78 / 6,59 \times 100 \%=\mathbf{2 6 , 9 4} \%$ \\
& Kondisi geologi dan iklim & $2,28 / 6,59 \times 100 \%=\mathbf{3 4 , 6 7} \%$ \\
\hline
\end{tabular}

\subsection{Pembahasan}

Dari hasil analisis dengan metode AHP kriteria kondisi geologi dan iklim lokasi pabrik adalah prioritas utama saat akan mendirikan pabrik tempe dengan bobot kriteria 34,67\%, hal ini dikarenakan geologi berpengaruh pada metode pekerjaan pembangunan fisik pabrik sedangkan iklim sangat berpengaruh pada produk tempe. Tempe merupakan makanan yang terbuat dari biji kedelai atau beberapa bahan lain yang diproses melalui fermentasi dari apa yang secara umum dikenal sebagai ragi tempe ${ }^{18)}$. Lewat proses fermentasi ini, biji kedelai mengalami proses penguraian menjadi senyawa sederhana sehingga mudah dicerna. Beberapa penyimpangan dan penyebab kegagalan pembuatan tempe adalah fermentasi yang tidak optimal dikarenakan kelembapan dan suhu yang tidak mendukung ${ }^{19}$. Kelembaban udara juga merupakan salah satu unsur yang mempengaruhi kondisi atau keadaan cuaca dan iklim di suatu wilayah tertentu. Kondisi yang optimal pada pembetukan tempe adalah pada suhu $42^{\circ} \mathrm{C}{ }^{20)}$. Dengan kondisi geologi dan iklim yang sesuai maka produk tempe akan sesuai dengan keinginan konsumen, karena hasil akhir produk adalah yang paling utama. Produk tempe yang memiliki kualitas terbaik akan bertahan dalam persaingan, maka kriteria geologi dan iklim menjadi prioritas utama menurut hasil analisa dengan AHP dalam penentuan lokasi pabrik tempe.

Prioritas selanjutnya adalah ketersediaan tenaga kerja dengan bobot 26,94\%, kriteria jarak pasar dan pemasaran dengan bobot 14,93\%, kriteria fasilitas transportasi dengan bobot 11,36\%, kriteria fasilitas pendukung dan utilitas dengan bobot 7,08\% dan terakhir adalah kriteria jarak lokasi pemasok bahan baku. Jarak lokasi pemasok bahan baku menjadi prioritas terakhir dalam penentuan lokasi pabrik tempe karena pasokan bahan baku tidak perlu dilakukan setiap hari, untuk bahan baku utama seperti kedalai bisa dipesan setiap satu bulan sekali. Hal ini akan berpengaruh pada anggaran transportasi saat mendatangkan bahan baku yang hanya dikeluarkan kurang lebih sebulan sekali. Berbeda halnya dengan anggaran untuk upah tenaga kerja yang dalam sistem pengupahannya adalah harian. Apabila mendatangkan tenaga kerja jauh dari pabrik maka anggaran transportasi pun akan masuk dalam list untuk tenaga kerja. Selain itu untuk kriteria jarak ke pasar dan pemasaran serta fasilitas transportasi juga akan ditempuh setiap hari, maka 
jarak pasar dan pemasaran serta fasilitas transportasi menjadi prioritas yang lebih penting daripada jarak dengan pemasok bahan baku. Sedangkan untuk kriteria ketersediaan fasilitas pendukung dan utilitas lebih tinggi daripada kriteria jarak pemasok bahan baku karena fasilitas pendukung dan utilitas juga digunakan setiap hari, namun hanya dengan cukup perawatan yang baik fasilitas pendukung dan utilitas akan optimal dalam pengorasian selama proses produksi.

\section{KESIMPULAN}

Dari penelitian yang dilakukan pada beberapa kriteria, dapat diambil kesimpulan bahwa skala prioritas penentuan lokasi pabrik tempe yang dihasilkan setelah dianalisis dengan AHP yaitu kondisi geologi dan iklim (34,67\%), ketersediaan tenaga kerja $(26,94 \%)$, jarak pasar dan pemasaran $(14,93 \%)$, fasilitas transportasi $(11,36 \%)$, fasilitas pendukung dan utilitas $(7,08 \%)$ dan jarak lokasi pemasok bahan baku (5,02\%). Dengan hasil dan pembahasan diatas responden mendahulukan kualitas produk, setelah itu melihat dari sisi biaya yang dikeluarkan dalam memilih prioritas kriteria lainnya. Hasil penelitian dan pembahasan yang ada, maka dapat disampaikan beberapa saran untuk penelitian selanjutnya, antara lain:

1. Menambahkan sub kriteria dalam pemilihan lokasi pabrik tempe, agar alternatif lokasi yang dipilih lebih detail.

2. Penggunaan metode AHP dalam pemilihan lokasi pabrik tempe perlu dibuat dengan software perhitungan agar lebih cepat dan mudah dalam penggunaan.

\section{UCAPAN TERIMA KASIH}

Terimakasih kepada semua pihak yang terlibat dan kepada responden yang telah berkenan meluangkan waktunya untuk mengisi kuesioner, sehingga penelitian ini dapat terlaksana dengan baik.

\section{DAFTAR PUSTAKA}

1) http://www.berdesa.com/apa-beda-ukm-dengan-umkm-ini-penjelasannya/diterbitkan oleh aryadji/berdesa - 26 Juni 2018

2) https://qazwa.id/blog/umkm/ diterbitkan oleh Dendy Herdianto - February 21, 2020

3) https://www.cnbcindonesia.com/news/20200109195447-4-129008/menperin-mimpiri-bisa-ekspor-tempe diterbitkan oleh Efrem Siregar, CNBC Indonesia - 09 January 2020

4) Sayuti, M. (2008). Analisis Kelayakan Pabrik. Yogyakarta: Graha Ilmu.

5) https://id.wikipedia.org/wiki/Pengamatan

6) Subagyo, P.Joko. (2011). Metodologi Penelitian Dalam Teori Dan Praktek. Jakarta: Aneka Cipta.

7) Sugiyono. (2005). Metode Penelitian Kuantitatif Kualitatif Dan R\&D. Bandung: Alfabeta 
8) Wahyuni, Sri dan Hartati, Sri. (2012). Sistem Pendukung Keputusan Model Fuzzy AHP Dalam Pemilihan Kualitas Perdagangan Batu Mulia. Jurnal, Jurusan Ilmu Komputer dan Elektronika, FMIPA UGM. Yogyakarta. ISSN: 1978-1520. Vol 6, No. 1, January 2012, pp. 43-54

9) https://ilmumanajemenindustri.com/faktor-faktor-penentuan-lokasi-pabrik/ diterbitkan oleh Budi Kho - July 21, 2017

10) Saaty, T.L. (1993). Pengambilan Keputusan bagi Para Pemimpin, Proses Analitik Untuk Pengambilan Keputusan Dalam Situasi Yang Kompleks. Jakarta: Pustaka Binaman Prestindo

11) Sega, Hanien Nia H, et al. (2012). Penentuan Faktor Prioritas Mahasiswa Dalam Memilih Telepon Seluler Merk Blackberry Dengan Fuzzy AHP. Jurnal, Jurusan Statistika, FSM, Universitas Diponegoro. Semarang.

12) https://ilmumanajemenindustri.com/faktor-faktor-penentuan-lokasi-pabrik/ diterbitkan oleh Budi Kho - July 21, 2017

13) Saaty. (1986). The Analytic Hierarchy Process. McGraw-Hill.

14) Saaty, T.L. (1993). Pengambilan Keputusan bagi Para Pemimpin, Proses Analitik Untuk Pengambilan Keputusan Dalam Situasi Yang Kompleks. Jakarta: Pustaka Binaman Prestindo.

15) Munthafa, Eva, Mubarok. (2017). Penerapan Metode Analytical Hierarchy Process Dalam Sistem Pendukung Keputusan Penentuan Mahasiswa Berprestasi. Jurusan Teknik Informatika Universitas Siliwangi. Jurnal Siliwangi Vol.3. No.2, 2017 Seri Sains dan Teknologi. ISSN 2477-3891.

16) Viarani, Oktri, Zadry. (2015). Analisis Pemilihan Pemasok Dengan Metode Analitycalhierarchyprocess Di Proyek Indarung VI PT Semen Padang. Jurusan Teknik Industri, Fakultas Teknik, Universitas Andalas, Padang. Jurnal Laporan Kerja Praktek, Vol. 14 No.1, April 2015:55-70. ISSN 2088-4842 / 2442-8795.

17) Noviandri, Rika, et al. Analisis Pemilihan Supplier Metallic Box Menggunakan Fuzzy Analytic Hierarchy Process (AHP). Jurusan Teknik Industri, Universitas Brawijaya. Jurnal Rekayasa Dan Manajemen Sistem Industri Vol. 3 No. 3 Teknik Industri Universitas Brawijaya.

18) Tim Penyusun oleh PUSIDO Badan Standardisasi Nasional. 2012. Tempe: Persembahan Indonesia untuk Dunia. Badan Standardisasi Nasional Jakarta.

19) http://eprints.polsri.ac.id/4639/3/BAB\%20II.pdf

20) Irwan, et al. (2017). Pembuatan Tempe. Jurnal Praktikum Aplikasi Bioteknologi Pangan. Universitas Hasanudin Makasar. 